\title{
Correction to: Patient engagement in Canada: a scoping review of the 'how' and 'what' of patient engagement in health research
}

Elizabeth Manafo*, Lisa Petermann, Ping Mason-Lai and Virginia Vandall-Walker

\section{Correction}

It has been highlighted that the original manuscript [1] contains a typesetting error in the name of Virginia Vandall-Walker. This was incorrectly captured as Virgnia Vandall-Walker in the original manuscript which has since been updated.

\section{Author details}

Patient Engagement Platform, Alberta SPOR SUPPORT Unit, Faculty of Health Disciplines, Athabasca University, 1 University Drive, Athabasca, Alberta T9S

3A3, Canada.

Received: 12 February 2018 Accepted: 12 February 2018

Published online: 14 March 2018

\section{Reference}

1. Manafo $E$, et al. Patient engagement in Canada: a scoping review of the

'how' and 'what' of patient engagement in health research. BMC Health Res Policy Syst. 2018;16:5. https://doi.org/10.1186/s12961-018-0282-4.

* Correspondence: emanafo@ryerson.ca

Patient Engagement Platform, Alberta SPOR SUPPORT Unit, Faculty of Health Disciplines, Athabasca University, 1 University Drive, Athabasca, Alberta T9S

3A3, Canada 